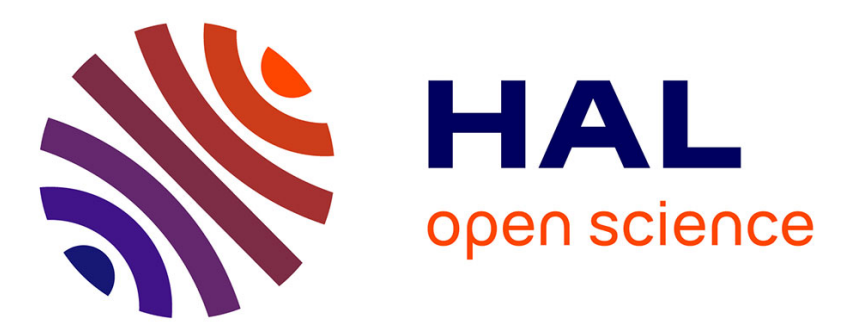

\title{
Pneumocystosis: a network survey in the Paris area 2003-2008
}

D. Magne, A. Angoulvant, F. Botterel, C. Bouges-Michel, M.-E. Bougnoux, P. Bouree, C. Chochillon, M. Cornet, E. Dannaoui, A. Fekkar, et al.

\section{- To cite this version:}

D. Magne, A. Angoulvant, F. Botterel, C. Bouges-Michel, M.-E. Bougnoux, et al.. Pneumocystosis: a network survey in the Paris area 2003-2008. European Journal of Clinical Microbiology and Infectious Diseases, 2011, 30 (5), pp.673-675. 10.1007/s10096-010-1139-0 . hal-00659520

\section{HAL Id: hal-00659520 \\ https://hal.science/hal-00659520}

Submitted on 13 Jan 2012

HAL is a multi-disciplinary open access archive for the deposit and dissemination of scientific research documents, whether they are published or not. The documents may come from teaching and research institutions in France or abroad, or from public or private research centers.
L'archive ouverte pluridisciplinaire HAL, est destinée au dépôt et à la diffusion de documents scientifiques de niveau recherche, publiés ou non, émanant des établissements d'enseignement et de recherche français ou étrangers, des laboratoires publics ou privés. 


\section{Pneumocystosis : A Network Survey in the Paris Area 2003-2008}

Denis Magnea, Adela Angoulvantb, Françoise Botterelc, Claire Bouges-Micheld, Marie-Elisabeth Bougnouxe, Patrice Bouree ${ }^{\mathrm{f}}$, Christian Chochillong, Muriel Corneth, Eric Dannaouii, Arnaud Fekkarj, Guy Galeazzik, Helene Yeral, Claudine Sarfati ${ }^{\mathrm{m}}$, and Patricia Rouxa

Assistance Publique - Hôpitaux de Paris (AP-HP), France : a : St Antoine, Paris ; b : Tenon, Paris ; c : Henri Mondor, Créteil ; d : Avicenne, Bobigny ; e : Necker, Paris, f : Kremlin-Bicêtre, Paris ; g : Bichat-Claude Bernard, Paris ; h: Hôtel Dieu, Paris ; i : Hôpital. Européen Georges Pompidou, Paris ; j: Pitié Salpétrière, Paris ; k: Louis Mourier, Colombes; 1 : Cochin, Paris ; $m$ : St Louis, Paris.

\section{Correspondance :}

Denis Magne

Parasitogie-Mycologie, Hôpital Saint Antoine, AP-HP

184, rue du Faubourg Saint Antoine

75571 Paris cedex 12, France

tel 33149282784

fax 33149283030

denis.magne@sat.aphp.fr 


\section{ABSTRACT}

The aims of this network are to collect epidemiological data of PcP cases in 14 hospitals in the Paris area and to determine the Di-Hydro Pteroate Synthase (DHPS) genotypes, genetic marker for possible sulfamide resistance.

From 01/01/2003 to 12/31/2007, 805 (mean: 161/year) PcP cases have been reported. $61 \%$ of patients were HIV-positive. The median count of CD4 lymphocytes was 32/mm3 (30 in HIV-positive patients, 158 in HIV-negative patients). In HIV-positive patients, PCP revealed the HIV infection in $39 \%$. Among 211 PCP occurring in HIV known infected patients, no prophylaxis was prescribed for $72 \%$; cotrimoxazole prophylaxis had been prescribed to 39 patients but only one of them had the right compliance. In HIV-negative patients (264), corticosteroids were prescribed in $54 \%$ and chemotherapy in $36 \% ; 93 \%$ did not receive prophylaxis. 128 tumoral pathologies and 86 transplantations were notified. The mortality rate was $16 \%$ at day 14 (13\% in HIV-positive patients, $26 \%$ in HIV-negative patients). Mutations in DHPS genes were detected in 51 samples; 33 patients were infected with several strains. Total annual number of cases has been stable for five years but the proportion of HIV-negative patients increased from $25 \%$ to $41 \%$.

KEYWORDS : Pneumocystosis, HIV, prophylaxis, cotrimoxazole, corticotherapy, DHPS 


\section{INTRODUCTION}

Despite a decrease in incidence associated with the introduction of the high antiretroviral therapies (HAART), pneumocystosis due to Pneumocystis jirovecii (or PcP for Pneumocystis pneumonia) remains one of the main fungal infection diagnosed in Europe in AIDS and other immunocompromised patients $[1,2]$. Due to strict host-species specificity, humans may be the main source of Pneumocystis jirovecii organisms and human-to-human and nosocomial transmission may occur [3]. Before the HAART era, HIV infection represented the main predisposing factors depending on the number of CD4 cells/ml. Genetic markers for possible sulfamide/sulfone-resistance (point mutations 165 and 171 of $P$. jirovecii dihydropteroate synthase (DHPS) gene, encoding for amino acid 55 and 57 of the protein) have been reported and are still debated [4]. The aims of this study were to revaluate the epidemiological characteristics of pneumocystosis in the Paris area and to analyse the relation between point mutation(s) in the DHPS gene and the breakthrough of prophylaxis.

\section{MATERIALS AND METHODS}

A network was initiated in 2003 to collect demographic and epidemiological data related to the cases of pneumocystosis diagnosed in 14 University hospitals of Assistance Publique - Hôpitaux de Paris (AP-

HP). Microscopic observations of bronchoalveolar lavage fluid (BALF) samples taken from these patients were performed using standard methods. These included Giemsa staining and the use of commercially available fluorescein-labeled monoclonal anti-Pneumocystis antibodies (BIORAD, Monofluokit Pneumocystis carinii) of BALF smears. Microscopic detection of the organism was taken as proof of PcP diagnosis. The following data were collected : date of birth, sex, department where analysis was performed, HIV serological status, PcP as HIV-revealing infection, immunosuppression due to other than HIV infection, solid organ transplantation information, tumor pathologies, immunosuppressive treatments, genetic immunodeficiency, date when the sample that revealed PcP was taken, first episode of $\mathrm{PcP}$ or no previous diagnosis, prophylaxis, intolerance or compliance to cotrimoxazole, CD4+ lymphocyte counts, initial treatment of PcP, and clinical progression. In addition, samples were analysed to determine DHPS genotypes (mutations at positions 165 and 171) using PCR direct sequencing. 


\section{RESULTS}

From 01/01/2003 to 12/31/2008, 993 cases of PcP were reported (mean : 166 cases/year). The sex ratio was 2.2 and the median age was 47 years. Sixty-five \% of the patients were HIV-positive. Among them, the HIV infection was already known in 304 patients, while pneumocystosis revealed the retroviral infection in $39 \%$ of the cases. The median count of CD4 lymphocytes was $30 / \mathrm{mm}^{3}+/-89 / \mathrm{mm}^{3}$ (range from 0 to 694). PcP was a first episode in $91.5 \%$. HIV-positive patients had not received any antiPneumocystis chemoprophylaxis at the time of pneumocystosis diagnosis in $64 \%$ of the cases. In the remaining cases, cotrimoxazole prophylaxis had been prescribed to 47 patients but only one of them had a right compliance. Drug intolerance was observed in $20.5 \%$ of these patients. When pyrimethamine + dapsone, atovaquone or pentamidine were used as prophylaxis, treatments were stopped in half cases because of intolerance to these drugs.

The proportion of HIV-negative patients $(n=264)$ increased from $25 \%$ of the cases in 2003 to $43 \%$ in 2008 (figure 1). The CD4+ lymphocytes count was $152 / \mathrm{mm}^{3}+/-264 / \mathrm{mm}^{3}$ (range from 0 to1000). In these patients, PcP was a first episode in $97.3 \%$ of cases. The main underlying diseases or risk factors were: haematological malignancies (73 leukemias, 51 lymphomas, 10 Hodgkin's diseases, 29 bone marrow transplantations, 5 myelomas), tumoral pathologies (169) and solid organ transplantations (116 transplantations; kidney : 48, heart :15: liver : 12, lung : 1). Fifty-nine $\%$ of the patients received corticosteroid therapy and $34 \%$ cytotoxic chemotherapies. Except tumoral pathologies and transplantations, the most frequent pathologies in HIV-negative patients were lupus (5), SCID (5), sarcoidosis (3), cirrhosis (3), dermatomyositis (3). Seventy-eight \% of the HIV-negative patients had not received any anti-Pneumocystis prophylaxis.

Mortality at day 14 was $26 \%$ in HIV-negative patients versus $13 \%$ in HIV-positive patients. When the diagnosis of PcP was performed, $44 \%$ of HIV-negative patients and $26 \%$ of HIV-positive patients were in units of intensive care.

Forty-two \% of specimens were available for DHPS genotyping. Forty six (14\%) of the samples did not amplify. Mutations in DHPS genes were detected in 18,5\% of samples. Co-infections with at least two different strains were observed in $12,5 \%$ of the isolates. Double mutation (at positions 165 and 171) was present in $9.5 \%$. No significant relationship was observed between mutation and outcome or mortality, nor between mutation and prophylaxis. 


\section{DISCUSSION}

From 01/01/2003 to 12/31/2008, the incidence of PcP in the Paris area is stable despite prophylaxis and frequent use of HAART in HIV-infected patients. It confirms previous data in 2003-2004 in the same geographical area [5]. PcP still often reveals HIV infection (39\% of the cases) indicating extensive lack of

HIV status testing. Among known HIV-infected patients when PcP was diagnosed, prophylaxis is often missing $(64 \%)$ or not in compliance when used.

The proportion of HIV-negative patients increased continuously from 2003 to 2008. The main risk factors in HIV-negative patients were corticotherapy and chemotherapies. Cotrimoxazole is difficult to use in case of haematological malignancies because of its cytological side effects. Alternative drugs with their own side effects are less effective against Pneumocystis. The CD4+ lymphocytes count is less relevant in these patients for PcP risk managing because the mechanisms of immunosuppression are different than in HIV infection [1].

Genotyping for DHPS gene was not effective for $14 \%$ of the specimens without any amplification; this is due to the fact that DHPS is present in single copy. The prevalence of DHPS mutations varies with geographic location and could be related to the frequency of chemotherapeutic drugs used to clear PcP

[6]. In our survey, no significant relationship was observed between mutation and outcome or mortality, or between mutation and prophylaxis. Indeed, mutations were detected in patients without prophylaxis. In $9.5 \%$ of the isolates, mutations were detected in both sites (165 and 171). Expression mutant genes in recombinant Saccharomyces cerevisiae systems showed that the presence of two mutations results in higher resistance than the presence of only one [6]. An initial mutation in P. jirovecii DHPS might first occur in drug-treated patients without clinical consequences and later other mutations could come about leading to the spread of organisms with high resistance to cotrimoxazole. So, the risk of emergence of resistant strains exists and epidemiological surveillance is needed

Despite risk factors and effective prophylaxis being known, PcP remains a frequent fungal disease associated with AIDS and in other immunocompromised patients as well. PcP still often reveals HIV infection at a late stage. Prophylaxis needs to be prescribed in patients receiving long-term corticosteroid treatment. 


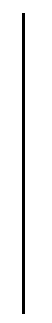




\section{REFERENCES}

[1] Roblot F, Godet C, Le Moal G, Garo B, Faouzi Souala F, Dary M et al. (2002) Analysis of underlying diseases and prognosis factors associated with Pneumocystis carinii pneumonia in immunocompromised HIV-negative patients. Eur J Clin Microbiol Infect Dis 21: 523-31.

[2] Magne D, Lacube P, Angoulvant A, Meliani L, Botterel F, Bougnoux ME et al. (2007)

Pneumocystosis : Survey in 14 Hospitals from Assistance publique-Hôpitaux de Paris (AP-HP), France, 2003-2005. Bulletin Epidémiologique Hebdomadaire, InVS (France), BEH 5/6 février 2007.

[3] Stringer J, Beard CB, Miller RF, Wakefield AE. (2002) A new name (Pneumocystis jirovecii) for Pneumocystis from humans. Emerg Infect Dis 8: 891-6.

[4] Meneau I, Sanglard D, Bille J, Hauser PM. (2004) Pneumocystis jirovecii dihydropteroate synthase polymorphisms confer resistance to sulfadoxine and sulfanilamide in Saccharomyces cerevisiae. Antimicrob Agents Chemother 48: 2610-6.

[5] Magne D., Lacube P., Angoulvant A., Meliani L., Botterel F., Bougnoux M.E., Chochillon C.,Cornet M., Dannaoui E., Datry A., Dunand J., Galeazzi G., Bouges-Michel C., Yera H., Sarfati C., Roux P. (2006) Pneumocystosis : survey and DHPS genotype analysis in 14 Parisian hospitals in 2003 and 2004. J Eukaryot Microbiol 53: S106-S107.

[6] Friaza V, Montes-Cano MA, Respaldiza N, Morilla R, Calderón EJ, de la Horra C. (2009) Prevalence of dihydropteroate synthase mutations in Spanish patients with HIV-associated Pneumocystis pneumonia. Diagn Microbiol Infect Dis 64:104-5.

[7] Moukhlis R, Boyer J, Lacube P, Bolognini J, Roux P, Hennequin C. (2010) Linking Pneumocystis jirovecii sulfamethoxazole resistance to the alleles of the DHPS gene using functional complementation in Saccharomyces cerevisiae. Clin Microbiol Infect $16: 501-7$. 
Figure 1. HIV serological status

positive

negative

unknown

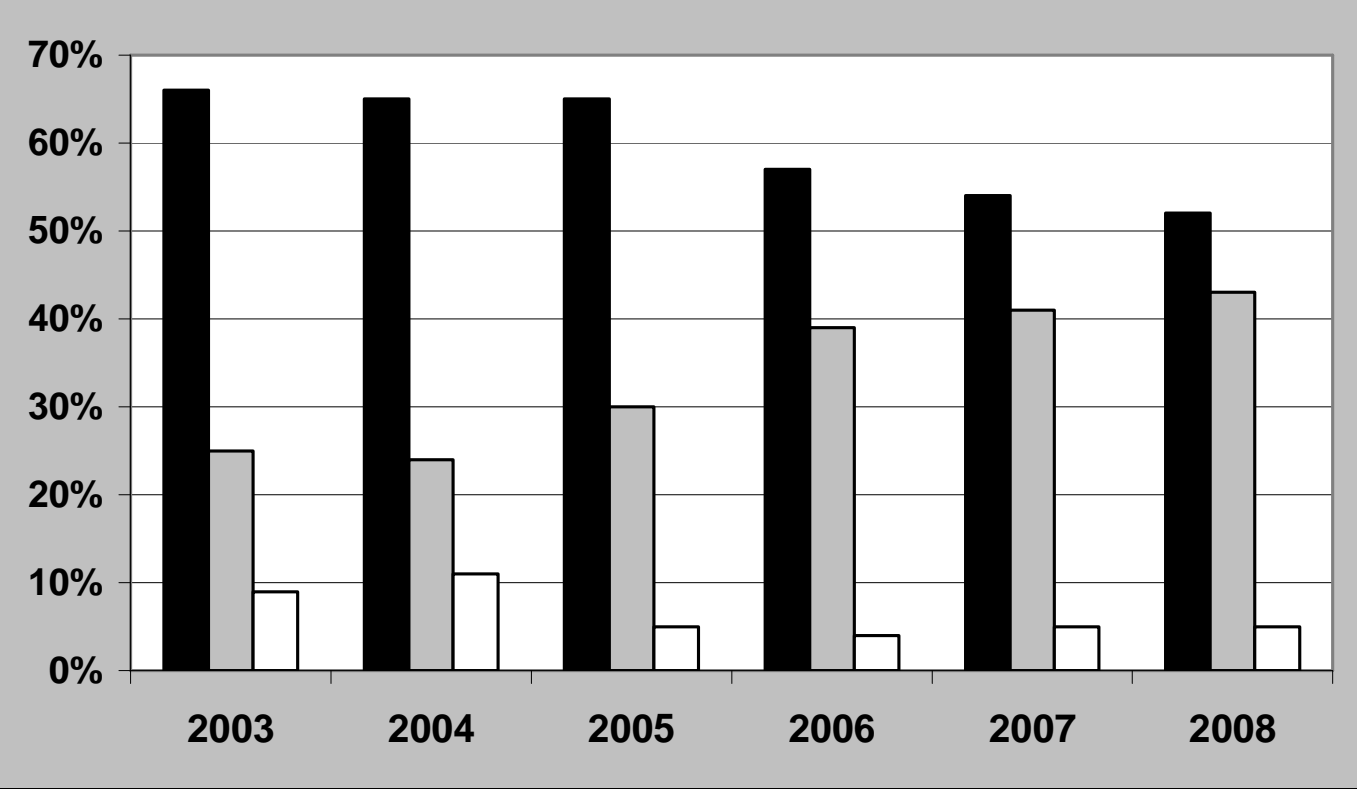

